\title{
Use of Virtual Reality Platforms in Design and Presentation Processes
}

\author{
Kubra Elif Sen (Corresponding author) \\ Faculty of Architecture and Design, Van Yuzuncu Yil University, Van, Turkey \\ E-mail: kubraelifsen@gmail.com \\ Onur Satir \\ Faculty of Architecture and Design, Van Yuzuncu Yil University, Van, Turkey \\ E-mail: osatir@yyu.edu.tr
}

\begin{abstract}
Virtual technologies and their potential innovations have developed significantly in recent years. Virtual reality, which is the subject of stories and stories in the field of literature, has been in our lives since the 1950s. It is used in many areas, including our daily life, and has also potential use in new areas. Virtual reality, which is used in the fields of health, tourism, architecture, education, medicine, ecommerce and agriculture, in addition to video and game activities, greatly facilitates human life. The most important of the facilities it provides is the diversity of usage areas and the fact that virtual reality environments provide the closest presentation to the reality. In this study, information was given about virtual reality platforms, tools used and usage sectors. It is aimed to discuss not only leisure time activity, but also a technology that facilitates us in all areas of life and the present and future potential of this technology.
\end{abstract}

Keywords: Virtual reality, Virtual visualization, Virtual environment, Design.

DOI: $10.7176 / \mathrm{JSTR} / 6-11-02$

\section{Sanal Gerçeklik Platformlarının Tasarım ve Sunum Süreçlerinde Kullanımı}

\begin{abstract}
Özet
Sanal teknolojiler ve getirdiği potansiyel yenilikler son yıllarda önemli ölçüde gelişme göstermiştir. Edebiyat alanında öykü ve hikayelere konu olan sanal gerçeklik 1950'li yıllardan beri hayatımızda yer almaktadır. Günlük yaşantımız dahil olmak üzere birçok alanda kullanılmakta ve yeni alanlarda da kullanım potansiyelleri vardır. Video ve oyun aktiviteleri dışında sağlık, turizm, mimarlık, eğitim, tıp, e-ticaret ve tarım alanlarında kullanılan sanal gerçeklik insan hayatını büyük ölçüde kolaylaştırmaktadır. Kullanım alanlarının çeşitliliği ve sanal gerçeklik ortamlarının gerçeğe en yakın sunum imkanı tanıması, sağladığı kolaylıkların en önemlisidir. Bu çalışmada sanal gerçeklik platformları, kullanılan araçlar ve kullanım sektörleri konularında bilgi verilmiştir. Sadece serbest zaman etkinliği değil, hayatın her alanında bize kolaylık sağlayan bir teknoloji olduğu ve bu teknolojinin günümüz ve gelecekteki potansiyellerinin tartışılması amaçlanmıştır.

Anahtar kelimeler: Sanal gerçeklik, Sanal görselleştirme, Sanal ortam, Tasarım.

\section{Giriş}

Gelişen toplumlarda insan sürekli değişen teknolojik dünyada yaşamak ve bu çeşitli teknolojilere ayak uydurmak zorundadır. Çünkü bilgi çağını yaşayan toplumlarda var olan bilgiler sürekli değişim halindedir. Bu sebeple modern toplumlar, eğitim alanında hem öğrenme hem de öğretim açısından yeni
\end{abstract}


yöntem ve teknikler üretebilmek adına bilimsel çalışmalar yapmaktadır (Çavaş ve ark. ,2004).

Değişen teknoloji insan yaşamının birçok alanında olduğu gibi içinde yaşadığı ortamlarda da değişikliğe yol açmış ve yaratılan sanal ortamlar "sanal mekan" tanımı ile bu alanın literatüründe kullanılmaya başlamıştır (Özen, 2006). Bilgisayar ve video oyunlarıyla bugün evlerimize girmiş olan sanal mekan olarak da adlandırılan sanal gerçeklik, bir "yerde" olduğunuzu hissettirebilmek için çeşitli duyusal bilgiler (görüntü, ses ve diğerleri) sağlayan üç boyutlu bir bilgisayar simülasyonu olarak tanımlanmaktadır. Başka bir tanımda sanal gerçeklik, katılımcılarına gerçekmiş hissi veren, bilgisayarlar tarafından yaratılan dinamik bir ortamla karşılıklı iletişim olanağı tanıyan, bir benzetim modelidir (Bayraktar ve Kaleli, 2007). Bize kendi ellerimizle yarattığımız gerçek dışı bir dünyada dolaşma ve yürüme olanaklarını sunmakta, tasarladığımız sistemleri kavrama ve algılama gücümüzü önemli ölçüde arttırmaktadır (Bayraktar ve Kaleli, 2007).

Sanal gerçekliğin tarihine bakıldığında ilk olarak karşımıza "Ray Bradbury" ve "William Gibson" isimleri çıkmaktadır. Ray Bradbury 1950'lerde The World The Children Made (Çocukların Ürettiği Dünya) adlı romanın, The Velt (Bozkır) adlı öyküsünde, betimlemeleri üç boyutlu bir biçimde aktarmakla birlikte ses ve koku gibi duyuları da verebilen bir sistemi konu edinmiştir. William Gibson ise 1984'deki Neuromancer adlı romanında, "Siberuzay" adını verdiği ve herkesin bağlanabileceği, sanal gerçeklik benzeri bir süper bilgisayar ağı sistemini anlatmıştır (Ekici ve Özer, 2019). Burada önemli olan her iki kişinin de edebiyatçı olmasıdır. Günümüzde gerçekleşen bilimsel ve teknolojik gelişmelerin bir kısmının yıllar öncesinden edebiyatçılar tarafından kurgulandığı bilinmektedir. Sanal gerçeklik kavramının ilk kez edebiyatçılar tarafından kullanılması, insanoğlunun hayal gücünün teknolojinin bir adım önünde olduğunu gösterir niteliktedir. Sanal gerçekliğin uygulama olarak gelişsim süreci 2. Dünya Savaşı'nın sonuna doğru yoğunlaşmıştır. Görüntü yönetmeni olan Morton Heiling, eğer izleyicilerin duyuları uyarılırsa hikayelerin içine daha çok çekileceklerini düşünmüştür. 1962 yılında Morton Heilig "Sensorama” adını verdiği ilk sanal gerçeklik simülatörünü icat etmiştir (Şekil 1) (Heiling 1962). Bu sistem, kullanıcıya 3B renkli görüntü, stereo ses, hareket, koku, hatta rüzgâr etkisi veren titreşimli bir koltuktan oluşmaktadır.

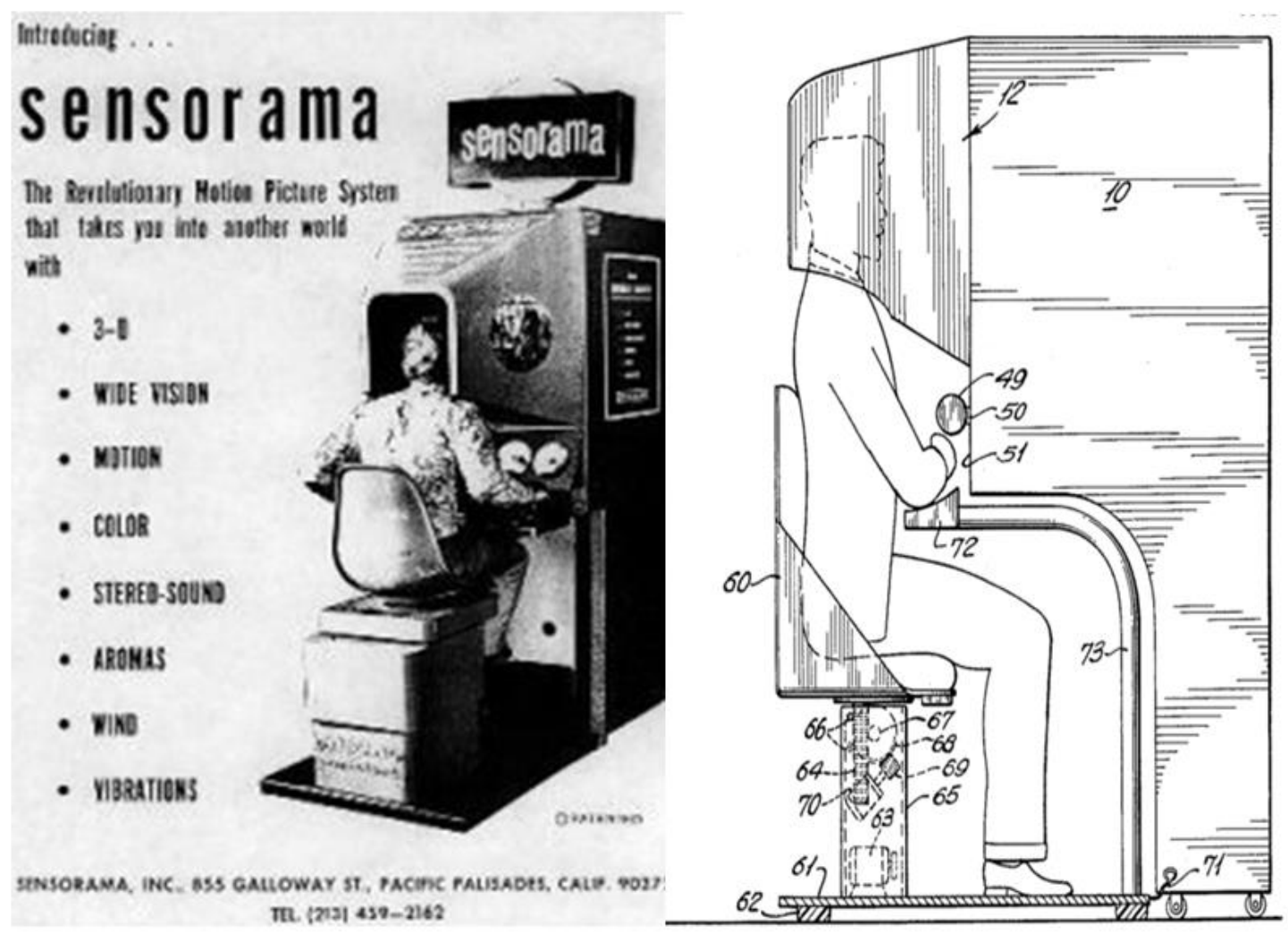

Şekil 1. Morton Heiling'in icat ettiği ilk sanal gerçeklik simülatörü sensorama 
Bilgisayarla oluşturulan grafiğin (Computer Graphics) babası sayılan Ivan Sutherland, 1966 yılında, bilgisayarların dış dünyadaki yazıcı, kalem, tarayıcı gibi aletlerle nasıl bir kombinasyon içerisinde kullanılabileceğini ve insan el çizim ve hareketlerinin bilgisayar ortamına aktarımı üzerine yaptı̆̆ çalışmalarla birlikte iki küçük ekrandan oluşan ve kullanıcının başına takabileceği elektro-optik bir sistem geliştirmiştir (Sutherland, 1966; Land and Sutherland, 1969). Tavandan sarkan mekanik kol ve kablolara asılı bu görüntü başlığını takan kullanıcı, daha kolay hareket etme olanağına kavuşmuştur (Şekil 2). Bu çalışma, günümüz modern sanal gerçeklik gözlükleri "Head Mounted Display” (HMD) için temel oluşturmuştur.
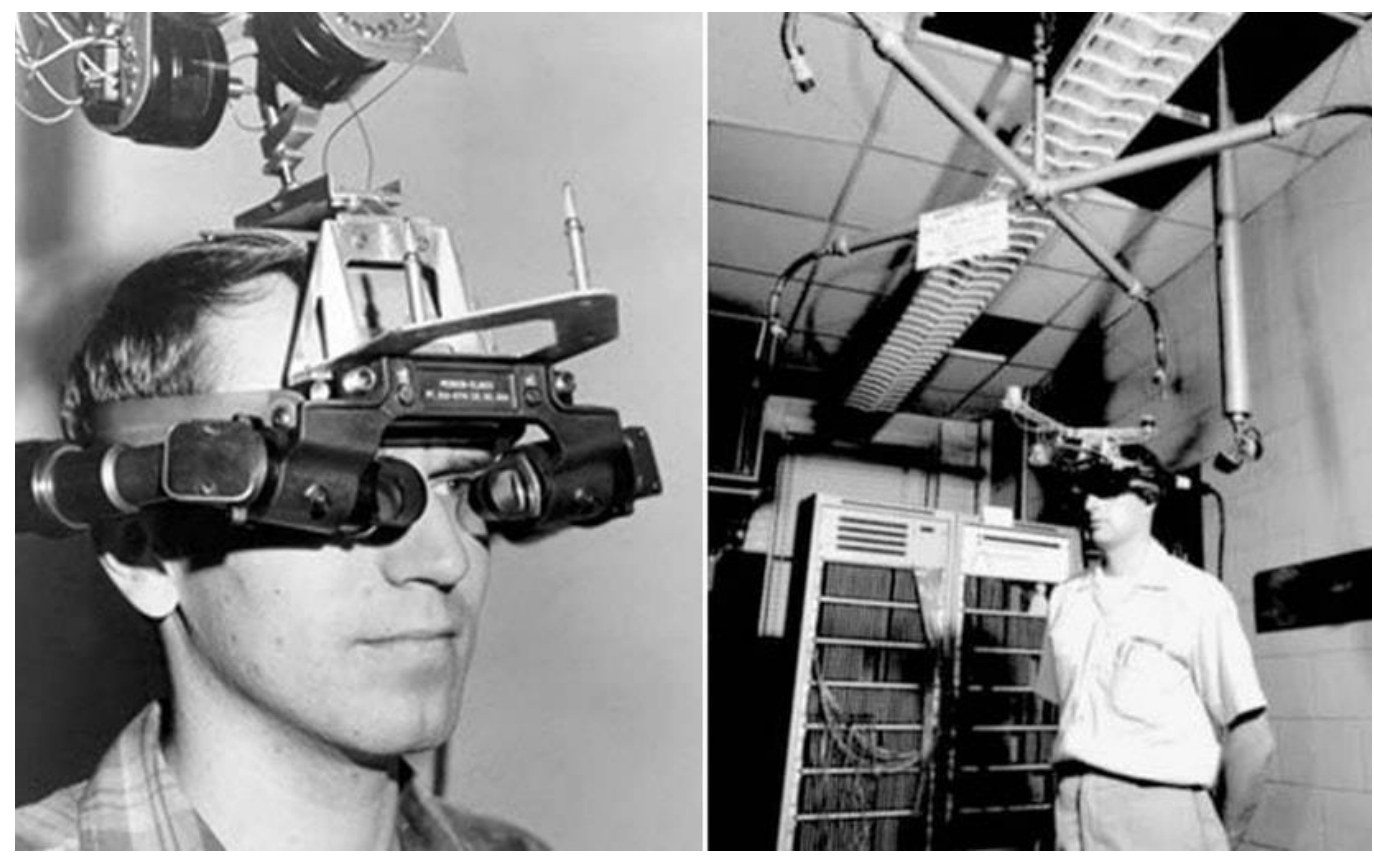

Şekil 2. Sutherland'ın geliştirdiği sanal gerçeklik görüntü başlığı.

$\mathrm{Bu}$ sistemlerin geliştirilmesinde en büyük desteklerden birisi de başta savunma ve uzay teknolojileri olmak üzere, eğitim öğretim süreçleri ve simülasyonların sayesinde olmuştur. Pilot, astronot ve askerlerin eğitimi için gerekli olan ortamları daha pratik ve ucuz karşılayabileceklerini düşünen savunma ve uzay sanayii çalışmaları ilgili teknolojilerin geliştirilmesinde itici bir güç sağlamıştır. Bu gibi çalışmalar en son örneklerden birisi uzay gemisi veya istasyonu için geliştirilen sanal öğrenme habitatıdır (Banerjee ve ark. 2020). Ferhat (2016)'ya göre Amerikan Havacılık ve Uzay Ajansı (NASA) 1980'lerde uzay araçları için tamir, bakım ve montaj gibi konularda uzaktan müdahale etme imkânlarını sanal gerçeklik teknolojileri ile desteklemiş ve astronot eğitim programlarında uygulamaya koymuştur.

Sanal görselleştirmenin en önemli özelliklerinden biri de katılımcılara gerçekmiş hissi vermesidir. Kullanıcı, bilgisayarların yaratmış olduğu ortamda istediği yere gidebilmeli, kontrolün kendi elinde olduğunu hissedebilmelidir. Sanal görselleştirme gözlüklerini içeren uygulamalarda, kullanıcı gideceği noktayı ve baktığı doğrultuyu etkileşimli olarak belirleyebilmektedir. Bir takım pozisyon izleyici aletlerin bu tür gözlüklerle birlikte desteklenmesi sayesinde, bilgisayar tarafindan yaratılmış ortamlarda yürümek mümkündür (Bayraktar ve Kaleli, 2007). Görme duyusunun yanı sıra ortamdaki sanal objelerin yerlerini değiştirme, dokunma, fiziksel özelliklerini hissetme ve çevredeki sesleri işitme gibi duyuları da Data Gloves olarak adlandırılan özel eldivenler ve üç boyutlu ses efektleri ile zenginleştirmek mümkündür.

Çavaş ve ark (2004)'e göre Brill 1994, sanal gerçeklik ortamlarında gerekli olan araç ve gereçler için bir sınıflama geliştirmiş ve bu ortamları 3 kısma ayırmıştır:

- $\quad$ Sahne (Stage)

- $\quad$ Masaüstü (Desktop)

- $\quad$ Aynalar Dünyası (Mirror World)

15 | P a g e 


\section{Sanal Gerçeklik Otamları}

\subsection{Sahne (Stage)}

$\mathrm{Bu}$ ortamda kullanıcı kendisinin tamamen sanal bir ortamda olduğunu hisseder ve bu ortam aşağıda tanımlanan 3 önemli araç ile açıklanabilir (Çavaş ve ark. ,2004):

\subsubsection{Başa Yerleştirilen Görüntü Verici Araç (Head Mounted Display, HDM)}

Sanal gerçeklik ortamında kullanıcı başına bir gözlük veya miğfer (HMD) takar (Şekil 3) ve kullanıcının sanal gerçeklik ortamında olma hissini sağlaması için kablo veya kablosuz yollarla bilgisayara bağlanır. Görüntü verici bu araçlar her göz için birer tane küçük görüntü veren ekran veya bütüncül bir ana ekran içerir, ayrıca kullanıcının sesleri algılaması için hoparlör veya kulaklık bulunur. Kullanıcının etrafına bakarken başın pozisyonunu ilgili yönde takip etmesini sağlayan bir algılayıcı da bulunmaktadır. $\mathrm{Bu}$ algılayıcılar günümüzde coğrafi verilerle bütünleştirilerek konumsal bilgi içeren GPS vb. ekipmanlarla donatılabilir. Bilgisayar miğferde bulunan algılayıcılardan gelen bilgileri düzenleyerek, 3 boyutlu sanal ortamla bütünleştirir ve bunu miğferde yer alan küçük ekranlara yansıtır. Sanal gerçeklik ortamında kullanıcının nesnelerle birlikte etkileşim içerisinde bulunabilmesi için HMD ile birlikte veri eldiveni (Data glove) veya bir tane manevra kolu (Joystick) kullanılır. $\mathrm{Bu}$ aletler sayesinde kullanıcı, ortama müdahale edebilir ve ortam içerisinde hareket edebilir (Şekil 4).

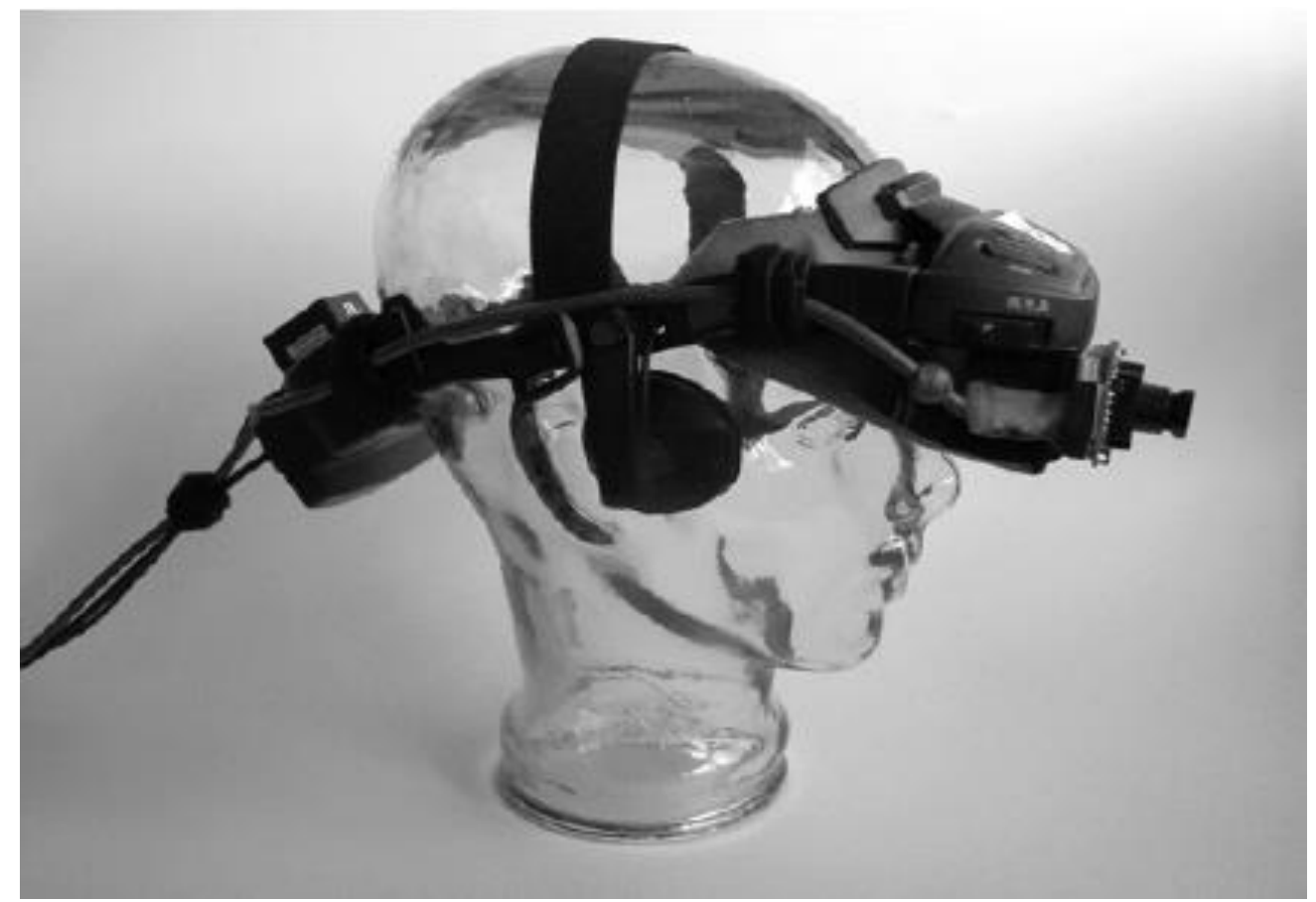

Şekil 3. Başa yerleştiren görüntü verici araç (Head Mounted Display, HMD)
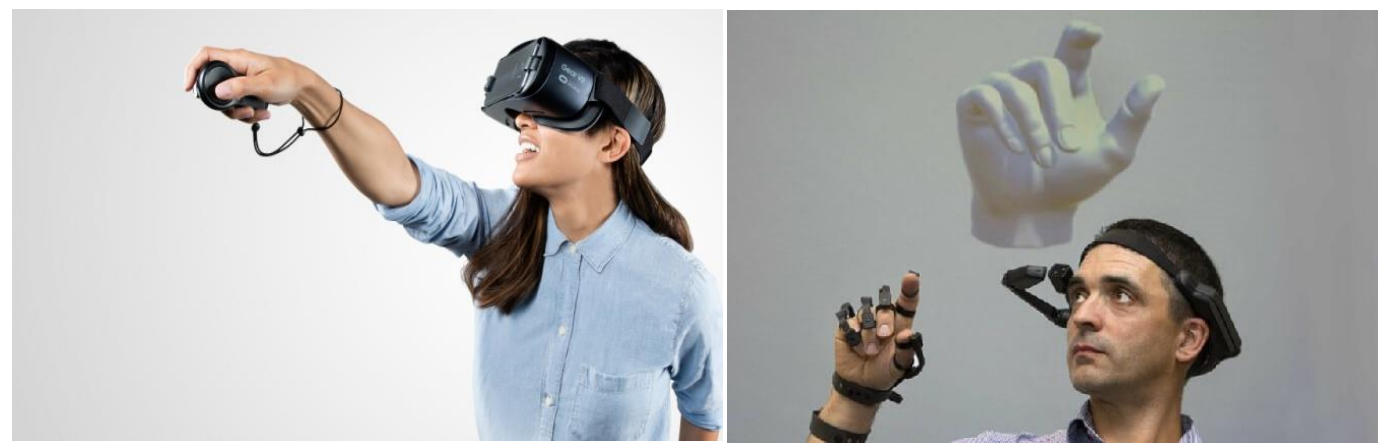

16 | $\mathrm{P}$ a g e 
Şekil 4. Manevra kolu (joystick) ve veri eldiveni (data glove) (www.androidcommunity.com, www.electricalfundablog.com ).

\subsubsection{Kabin Simülatörleri (Cab Simulators)}

$\mathrm{Bu}$ simülatörlerden günümüzde en çok bilinenleri uçak similatörleridir. Eğitim amaçlı olarak kullanımları yaygındır. Pahalı veya riskli ekipmanların doğrudan tecrübe edilmeden, gerçeğine en yakın şekilde canlandırılarak tecrübe edilmesine olanak sağlar (Şekil 5).

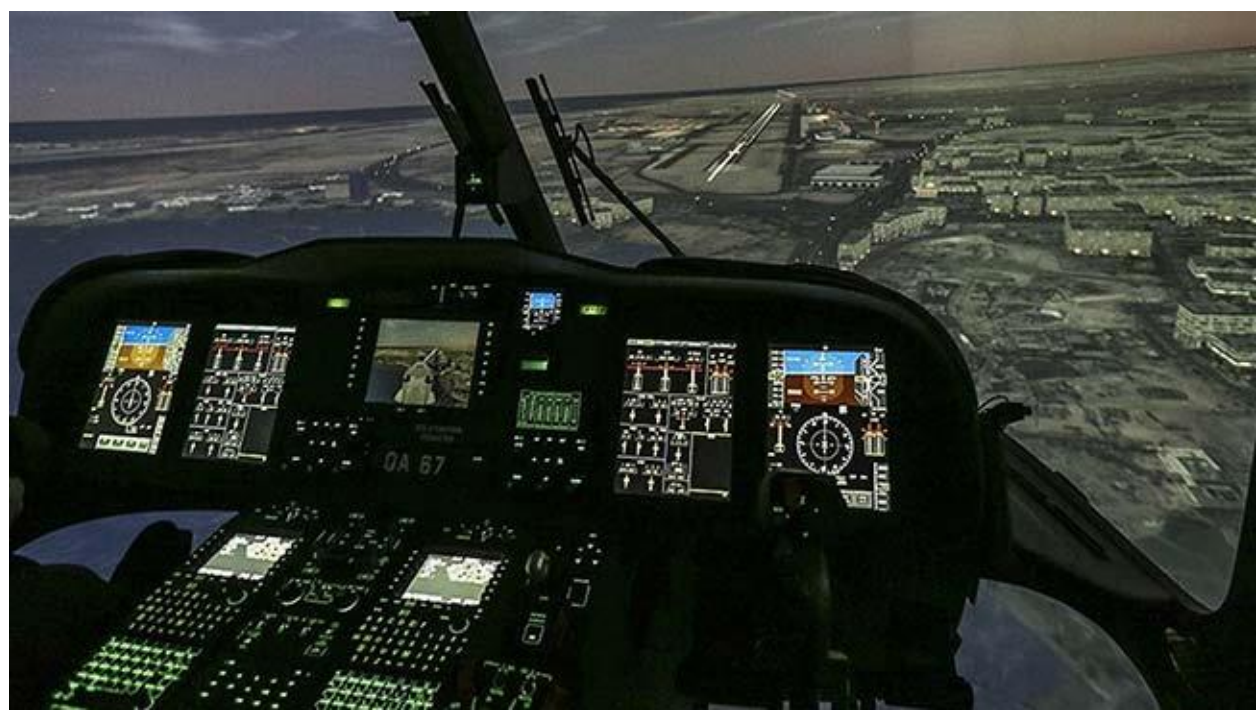

Şekil 5. Kabin tipi uçuş simülatörü

\subsubsection{Oda Dünyası (Chamber Worlds)}

Özel olarak donatılmış odalarda kullanıcı, tavana, zemine ve duvarlara nesnelerin bir sanal dünya oluşturulur ve kullanıcı donanıma göre 3 boyutlu görüntüleme yapan gözlükler de giyebilir. Bu gibi sanal gerçeklik ortamlarında kullanıcılar hem çevre hem de ortamda bulunan diğer kişiler ile de etkileşimde bulunabilmektedirler (Şekil 6).

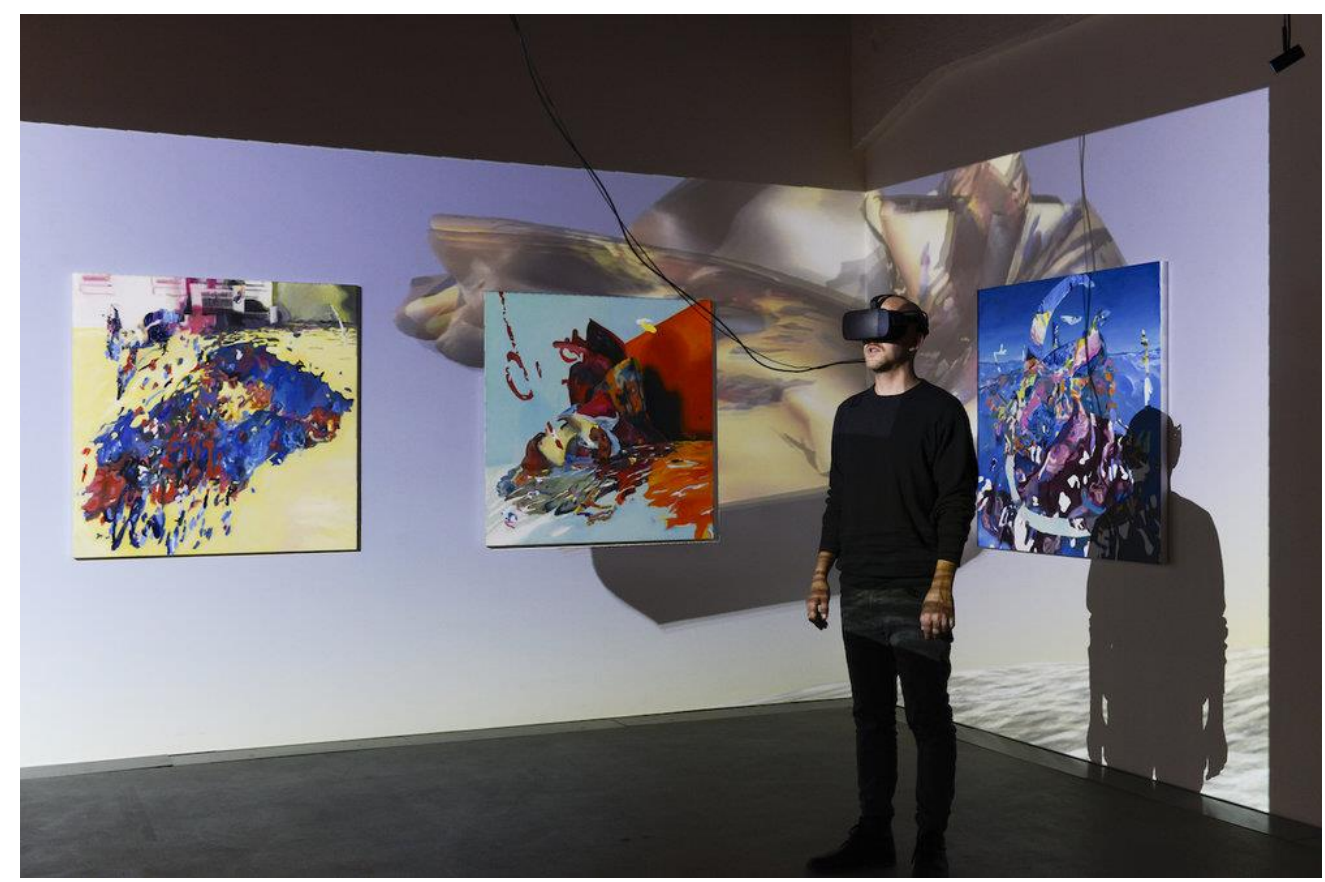

Şekil 6. Sanatsal ortam olarak özleştirilmiş sanal gerçeklik odası (www.peertospace.eu).

17| P a g e

www.iiste.org 


\subsection{Masaüstü (Desktop World)}

\subsubsection{Masaüstü Sanal Gerçeklik (Desktop Virtual Reality)}

$\mathrm{Bu}$ ortamda kullanıcılar, veri eldiveni, fare, sanal gerçeklik gözlüğü gibi ekipmanlar kullanmaktadırlar. Kullanıcılar kendilerini bu cihazlarla sistemin içerisinde yönlendirebilmektedirler (Şekil 7).
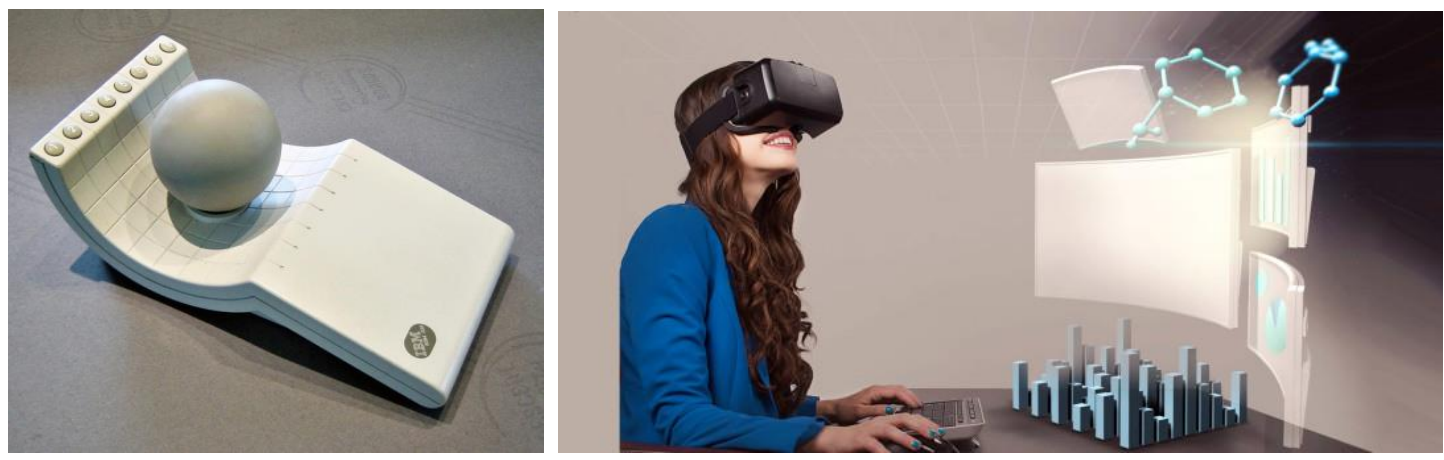

Şekil 7. Spaceball input ve masaüstü sanal gerçeklik ( www.makeuseof.com).

\subsubsection{Başa Bağlı Ekran (Head Coupled Display)}

$\mathrm{Bu}$ cihaz, tıp ilmindeki çeşitli robot ameliyatlarındaki sisteme benzer. Belirli bir yere sabitlenmiş bir gözlük ve yönlendirme aparatları sayesinde kontrol edilir. Kontrol esnasında vücut hareketlidir. Ayrıca hareketli nesneleri de içindeymiş gibi kontrol etmeyi sağlayabilir. Ancak kullanıcı bu sistemde farklı yönlere bakmak veya hareket etmek istediğinde diğer gözlüklü serbest sistemlere göre daha çok zorlanır. Öte yandan kullanıcı, hassas hareketler içinde daha güvenlidir (Şekil 8).

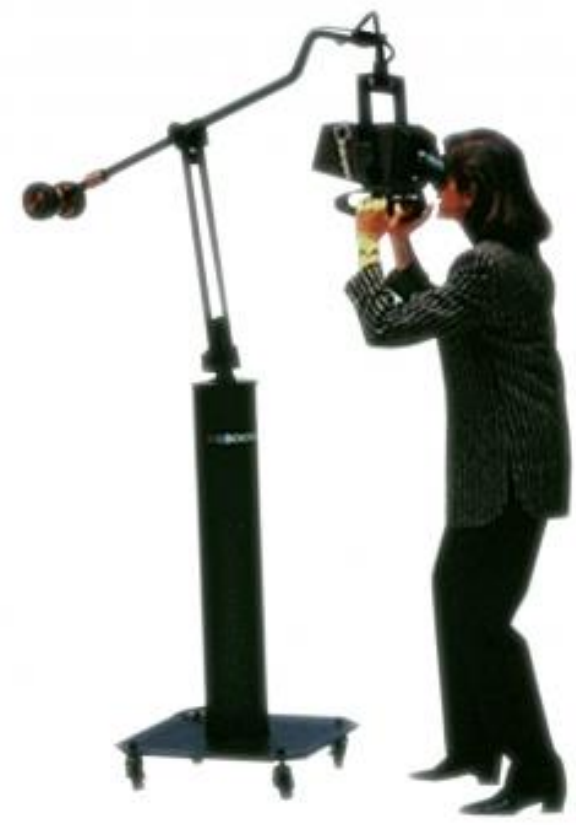

Şekil 8. Başa bağlı ekran cihazı (www.emaze.com).

\subsection{Aynalar Dünyası (Mirror World)}

$\mathrm{Bu}$ ortamda kişiler, bir ekran karşısında gerçek zamanlı olarak gerçek ve sanal mekanlar arasında etkileşim içerisindedirler. Bu sistemi, eş zamanlı aktarmak için, kamera, ekran ve yazılım desteği gerekmektedir. Bu sistemi basit olarak Sato ve ark. (2009)'da tanımlamışlardır. Bu sistemi kullanarak, mağazalarda kıyafetleri denemeden üzerindeymiş gibi görmek veya belirli bir alanı olduğundan farklı göstermek mümkündür (Şekil 9). 

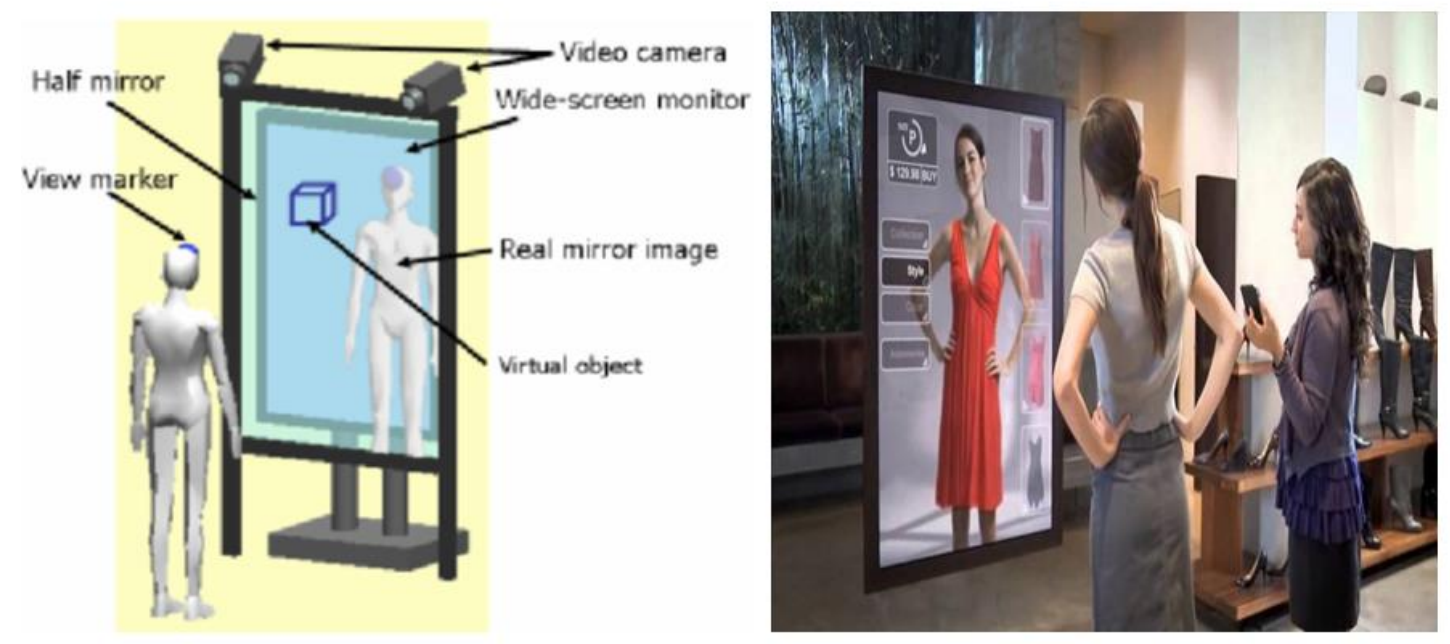

Şekil 9. Aynalar dünyası

\section{Sanal Gerçeklik ve Kullanım Alanları}

Porett (1994)'e göre verilerini soyut bir alandan alan dijital ortam ve araçlar, sınırlı olarak algıladığımız fiziksel gerçekliğin doğasını; analiz etme, yorumlama, dönüştürme ve hatta yeni baştan kurabilme olanağı sunmaktadır (Kuruüzümcü, 2010). Bu sayede sanal gerçeklik günümüzde birçok alanda kullanılmakta, gelişmekte ve fayda sağlamaktadır.

Hayatımıza ilk olarak eğlence dünyasıyla giren sanal gerçeklik uygulamaları, pek çok bilim kurgu filmleri, sinema, video oyunları gibi alanlarda farklı unsurlar kullanılarak büyük etki oluşturmuştur. Bir gözlük, eldiven veya el aparatlarıyla oyunun içindeymiş gibi hissetme imkanı vermesi açısından sanal gerçeklik platformları günümüzde bir çok oyun konsoluyla bütünleştirilmeye başlanmıştır. Günümüzde sinema, televizyon, haber sunumu, film montajı vb. birçok eğlence sektöründe aktif olarak kullanılmaktadır.

Bir diğer kullanım alanı turizimdir. Fransa'nın Burgundy bölgesinde Fransız devrimi sonrasında yok edilen manastır 'The abbey of Cluncy', arşiv kayıtlarından sanal görselleştirme yardımıyla bilgisayarda yeniden inşa edilerek isteyenlerin sanal görselleştirme yoluyla bu binanın katlarında dolaşabilmeleri ve duvarlarındaki en ince ayrıntıları dahi izleyebilmeleri sağlanmıştır (Şekil 10) (Bayraktar ve Kaleli, 2007).

Eğitim alanında da kullanılan sanal gerçeklik, öğrencileri öğrenmeye teşvik ederken öğretmenlerin de yükünü azaltmaya yardımcı olmaktadır. Öğretmenler, öğrencilerin sorularını sadece cevaplayan kişiler olmaktan ziyade, öğrencilerin kendi kendilerine keşfetmelerinde ve yeni fikirler üretmelerinde rehberlik yaparlar (Çavaş ve ark. 2004). Pilotların, astronotların ve güvenlik görevlilerinin aksiyon ortamlarında eğitimlerinde de aktif olarak kullanılmaktadır (Şekil 5). Ayrıca günümüzde uzaktan eğitim platformları ile birlikte, derslerin aktif sınıf ortamında anlatılması ve bazı laboratuvar ortamları gerektiren derslerin işlenmesinde kullanılmaya başlanmıştır.

Tıp ve cerrahi uygulamalar alanında sanal görselleştirme her geçen gün daha çok ilgi görmektedir. Oluşturulan sanal kadavra yoluyla tip eğitimini alan öğrencilerin kadavra üzerinde sayısı denemeler yapabilmeleri sağlanmakta, öğrenci kas ve kemik üzerinde incelemeler yaparken kas ve kemiklerin bisturiye karşı direncini hissedebilmektedir (Şekil 11). Ayrıca doktorlar hayati operasyonları, önce sanal bir ortamda tecrübe ederek tedavi sürecinin hastaya olan etkilerini daha iyi anlayabilmektedir (Bayraktar ve Kaleli, 2007).

Sanal görselleştirme tarımsal araştırmalar alanında da kullanılmaktadır. Bitkiler için yapılan bilgisayar modelleri ve görselleştirme tarımsal bilişim alanında önemli bir konudur. Sanal bitki, üç boyutlu bir uzayda bir bitkinin büyüme sürecinin ve yapısal gelişiminin bilgisayar simülasyonudur (Şekil 12) (Xiong ve ark., 2006). Bitkilerin grafik veya görüntülerinin üretilmesine yönelik olarak bilgisayarcılar, botanikçiler ve matematikçiler tarafindan birçok model geliştirilmiştir. Geliştirilen bu modellerle sadece sanal bitkiler değil, sanal alanlar ve çevreler de üretilebilmektedir. Sanal bitkiler, bitkinin gelişim hızı gibi bitki gelişimine ait bilgilere göre Visual C, Delphi, Visual Basic, vb. gibi genel programlama dilleri kullanılarak oluşturulabilmektedir. Sanal bitkiler araştırmalarda ve tarımsal

19 | P a g e

www.iiste.org 
gelişimde önemli roller oynayacaktır. Örneğin zamandan ve paradan tasarruf sağlamak için sanal bitkiler, sanal deneyler ile geliştirilebilir. $\mathrm{Bu}$ sanal deneyler, bitkilerin gelişim kurallarının keşfedilmesine yardımcı olacak ve çiftlik yöneticilerinin uygun kararlar almasını kolaylaştıracaktır (Xiong ve ark., 2006).

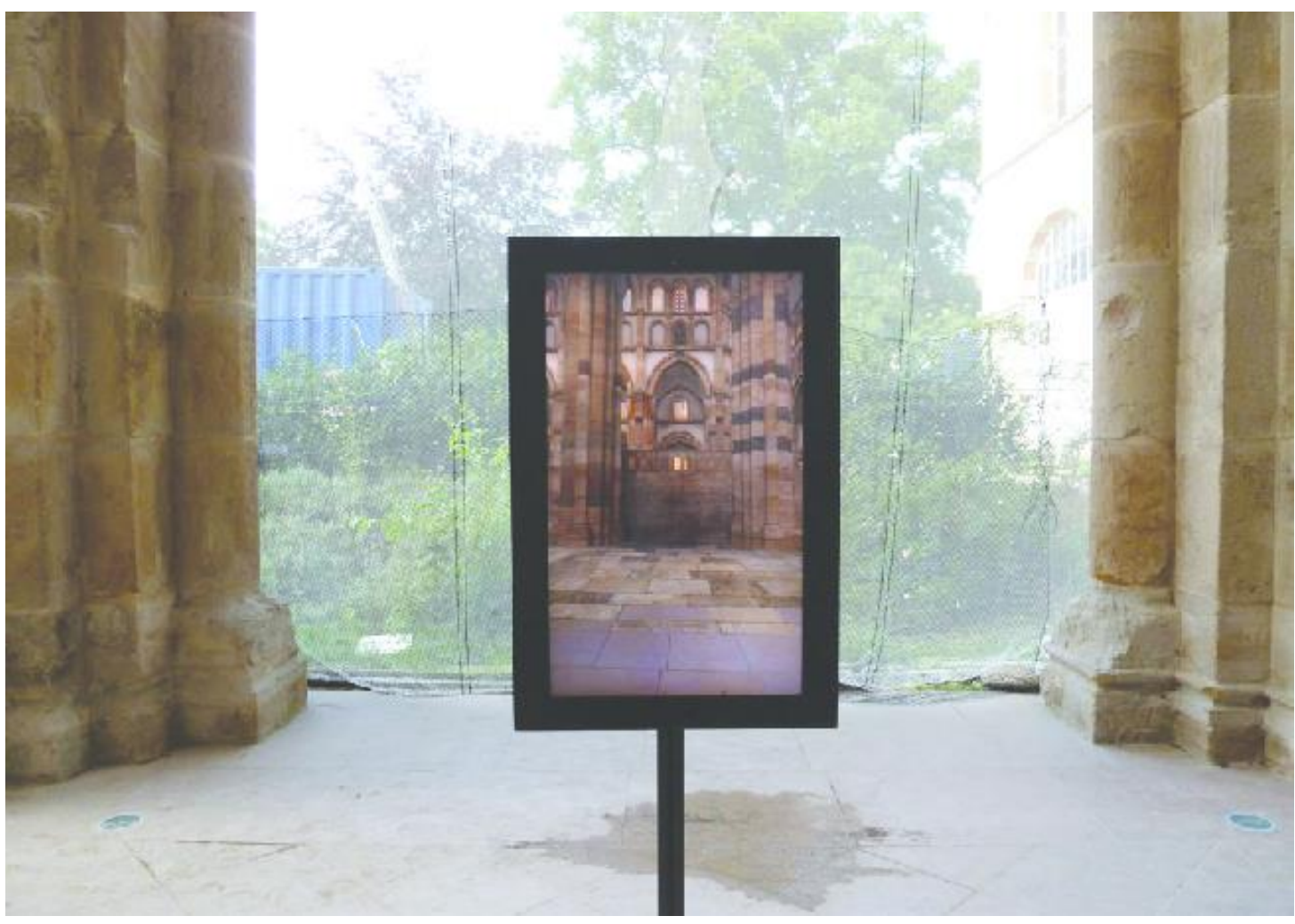

Şekil 10. Fransa'da bulunan manastırın sanal görselleştirme yardımıyla yeniden inşa edilmesi

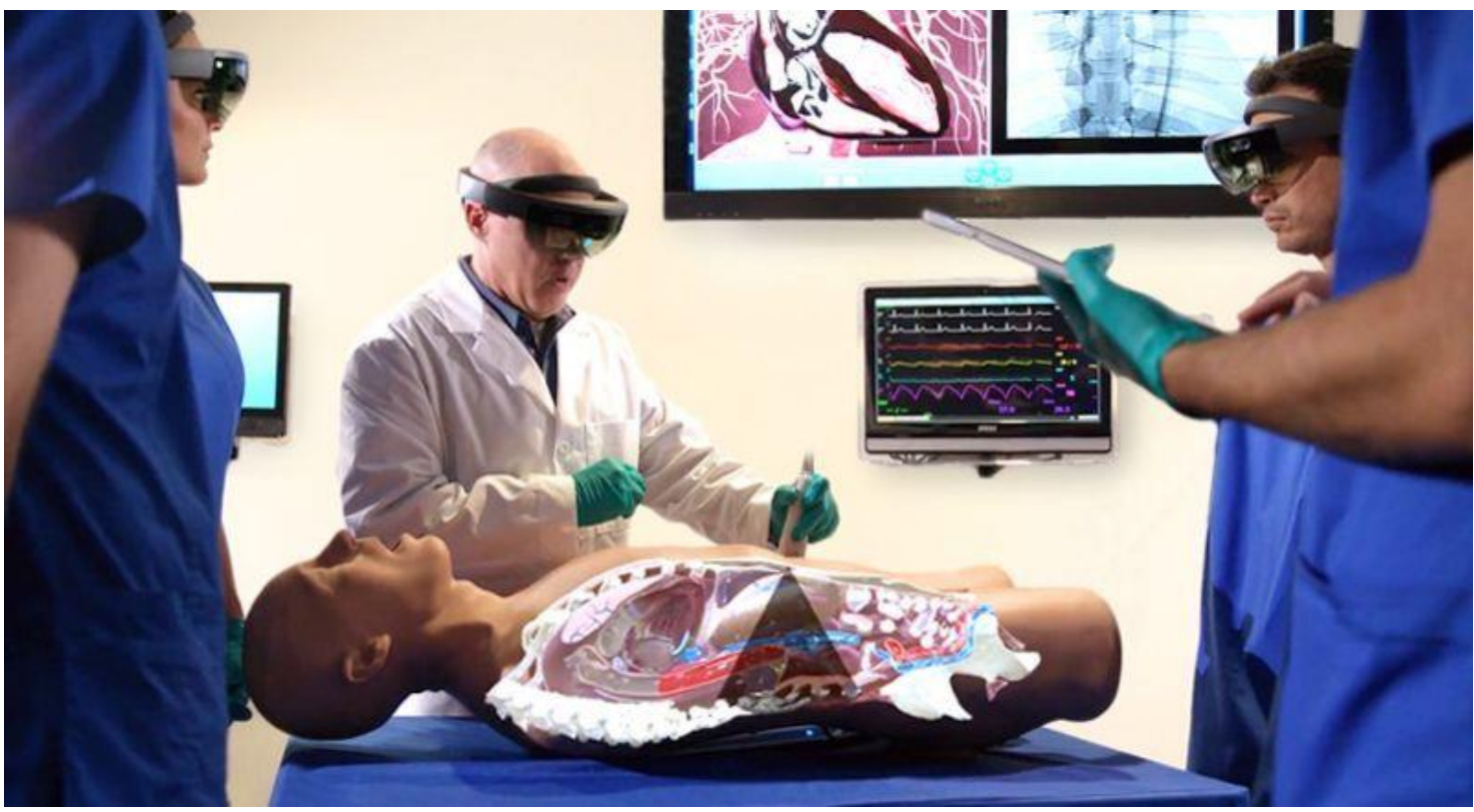

Şekil 11. Sanal gerçekliğin tıp alanında kullanımı (www.simlabit.com). 


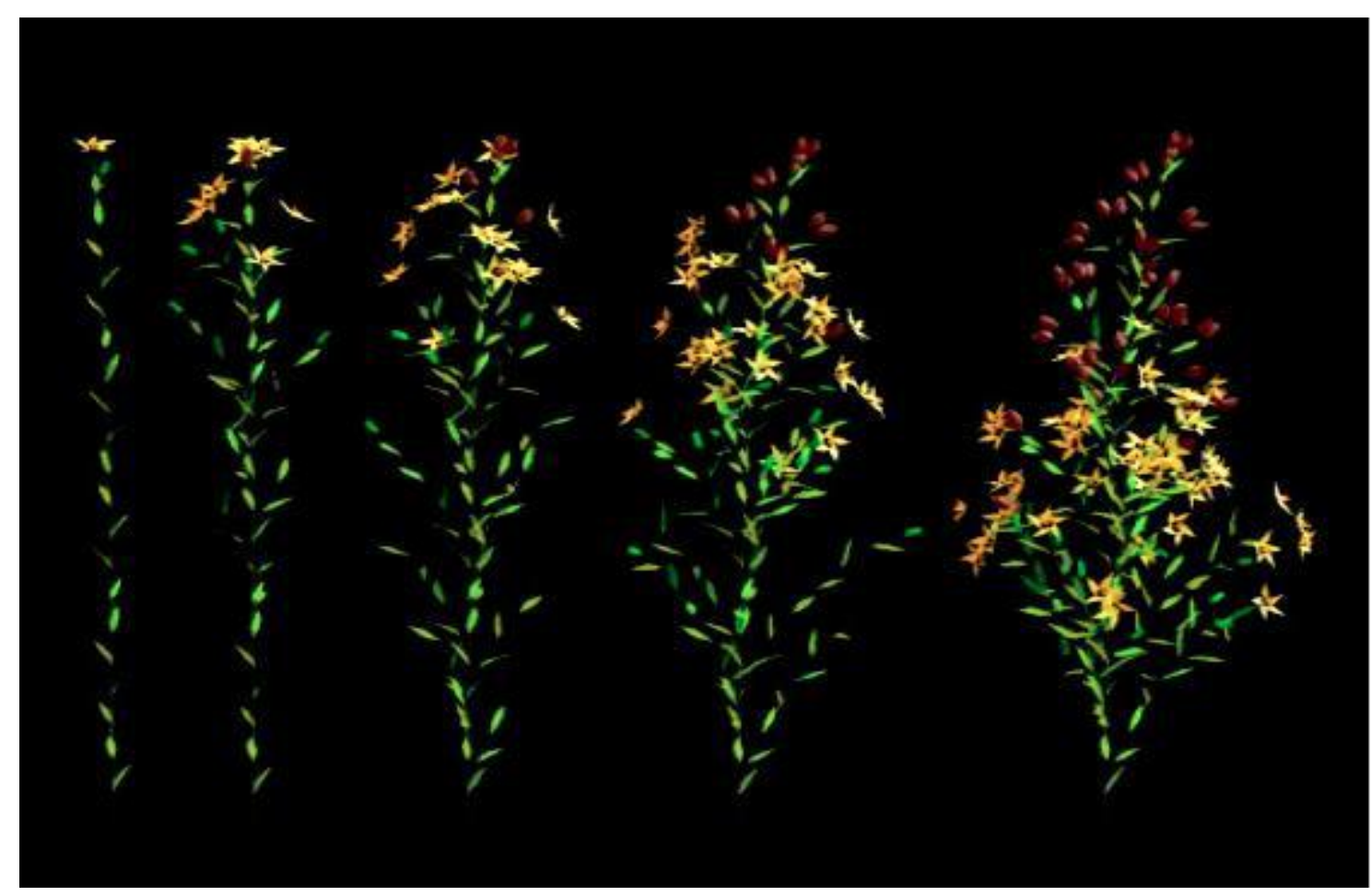

Şekil 12. Bir bitkinin çiçek sıklığı ve gelişme işlemi

Bilgisayar destekli tasarım alanları arasında yer alan mimarlık, peyzaj mimarlı̆̆ı, endüstri ürünleri tasarımı, iç mimarlık ve şehir ve bölge planlama ile moda tasarımı gibi gündelik hayata yönelik ürünler üreten sektörler içinde sanal gerçeklik uygulamaları, özellikle maliyetin azaltılması, sunum etkinliği ve müşteri memnuniyeti açısından önemli bir potansiyel oluşturmaktadır. Sanal gerçeklik uygulamalarını kullanarak mimarlar projesi tamamlanmış bir tasarımı alıcılarına gösterebilirler (Şekerci, 2017). İlgili disiplinlerdeki tasarımcılar, tasarladıkları mekanı, hayatı veya objeyi uygulamaya geçirmeden canlandırabilir ve müşterilerine sunabilirler. Böylece, müşterinin istediği gerekli revizyon işlemleri, her hangi bir prototip üretmeden tamamlanabilir ve nihai tasarım, müşteri memnuniyeti açısından kusursuza yakın yapılabilir. Ayrıca tasarımcılar, uygulama sırasında oluşabilecek aksaklıkları önceden görebilir ve tasarımlarını revize edebilirler.

Sanchez ve ark. (2017)'de kentin içerisinden geçmesi düşünülen bir raylı sistemin, güzergahı içerisinde yaşayan kent sakinlerine vereceği gürültü kirliliği etkisini, önceden öğrenmek ve gerekli tedbirleri almak için sanal gerçeklik ortamında ilgili bölgenin ve raylı sistemin modelini geliştirmişlerdir. Görüntü ve ses efektleriyle zenginleștirilen modelde, gürültü ve görsel kirliliğin, bölgede yaşayanlara etkisini, proje yapılmadan test etme imkanı bulmuşlar ve buna göre proje revizyonlarının nerelerde yapılması gerektiğini ve ses bariyerlerinin konulacağı bölgeleri belirlemişlerdir (Şekil 13).

Şekerci (2017)'de mekân tasarımında sanal gerçeklik teknolojilerinin kullanımının tasarımcı üzerinde etkilerini aşağıdaki şekilde sıralamıștır;

- Mekân tasarım sürecinde daha hızlı sonuç almayı ve farklı alternatifleri değerlendirmeyi sağlar.

- Tasarımcıya gerçeklik hissi vererek tasarımcıya kontrolün kendi elinde olduğu hissini verir.

- Karşılıklı etkileşim sağlar

- Gerçekte var olan fakat tasarımcının keşfetme ve inceleme olanaklarını bulamadığı mekanları incelemesini sağlar.

- Meydana getirilmesi mümkün olmayan tasarımların oluşmasına kolaylık sağlar.

- Tasarımcıya tasarımın en ufak parçalarına kadar görselleştirerek derinlemesine analiz etmesini sağlar.

- Farklı yerlerde olan tasarımcıların bir araya gelmesini sağlar ve ortak projeler oluşturmasını sağlar.

- Soyut tasarımları farklı açılarla görmeyi sağlayarak öğrenmenin daha hızlı ve kaliteli olmasını sağlar.

21 P a g e

www.iiste.org 

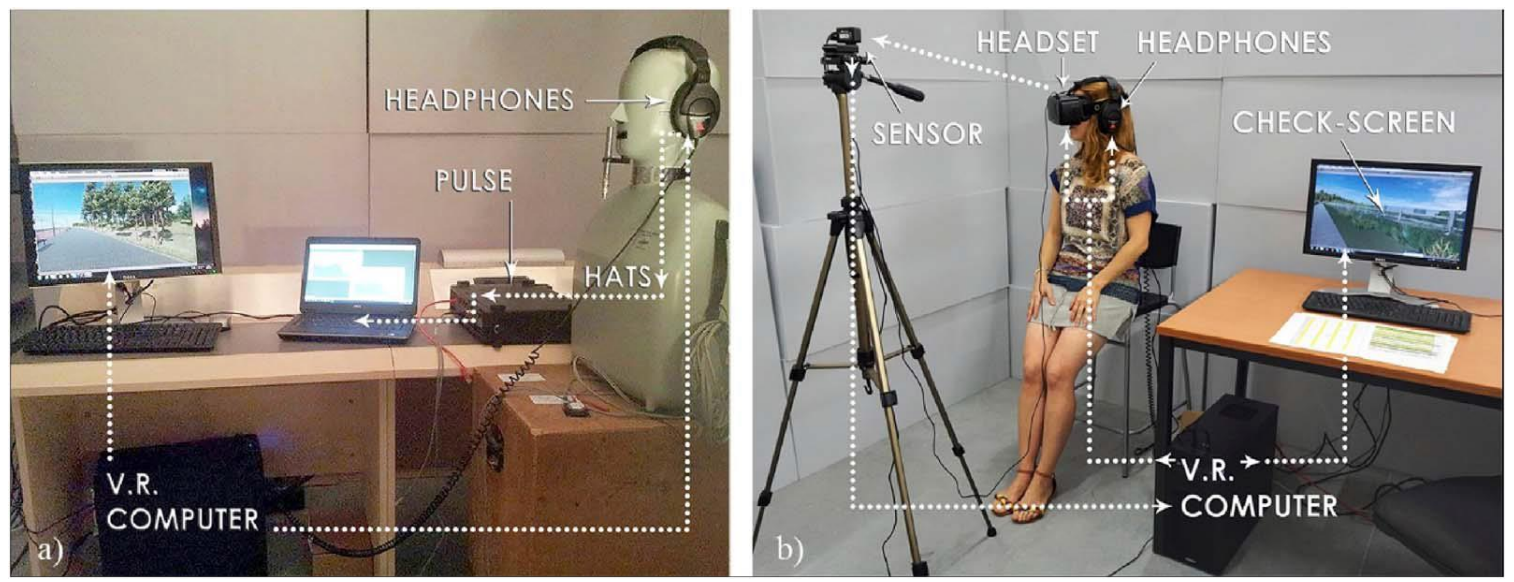

Şekil 13. Sanchez ve ark (2017)'de kullanılan canlandırma sistemi

\section{Sonuc}

Sonuç olarak sanal gerçeklik platformları, özellikle görsel ve işitsel duyulara hitap ederek, kullanıcıya sanal ortamda üretilen mekan veya nesneleri, gerçeğine yakın tecrübe ederek deneyimleme imkanı sunmaktadır. Bu teknoloji ilerleyen süreçlerde grafik özellikler açısından ve daha fazla duyu organına hitap edecek şekilde geliştirilerek, teknolojisini iyileştirecek ve daha fazla sektörde kullanılmaya başlanabilecektir.

Günümüzde en çok kullanılan sektörler; eğlence, pilot eğitimleri, tasarım, planlama, e-pazarlama ve turizm sektörleridir. Ayrıca; tıp, her düzeyde okul öğrencisi için uzaktan eğitim, sanal açık hava müzeleri oluşturulması, pandemi gibi dönemlerde stadyumdan canlı maç izlenmesi, kişisel medya operatörleri, risk yönetimi ve algısı gibi bir çok sektörde kullanım potansiyeli çok yüksektir. Gelecekte bu konuyla ilgili bir çok şirketin ortaya çıkması beklenmektedir, çünkü gerek akademik yayın sayısı olarak, gerekse uygulamada son birkaç yıldır yaygınlaştı̆̆ görülmektedir. Her ne kadar konuyla ilgili ilk uygulamalar $1960^{\prime}{ }^{\prime}$ y yllara kadar gitse de pratik ekipmanlarla sanal gerçeklik ortamının oluşturulması son 10 yıllık süreçte mümkün olmuştur. Akademik açıdan bakıldığında ise 1995 'de hayata geçen ve Springer yayın evi tarafindan basılan "Virtual Reality" dergisi etki faktörü en yüksek dergidir. Web of Science veri tabanında SCI-Exp süreci içerisinde değerlendirilen sadece 4 adet konuyla doğrudan ilgili dergi bulunmaktadır. Bu durumda, genel olarak Sanal gerçeklik konularının halen çalışılması gerektiğini ortaya koymaktadır.

\section{Referanslar}

Bayraktar, E., Kaleli, F. (2007), "Sanal Gerçeklik ve Uygulama Alanları", IX. Akedemik Bilişim Konferansı Bildirileri, 2007, 315-321.

Banerjee, N.T., Bauhgman, A.J., Lin, S.Y., Witte, Z.A., Klaus, D.M., Anderson, A.P. (2019). "Development of alternative reality environments for spacecraft habitat design evaluation" Virtual Reality, DOI: 10.1007/s10055-020-00462-6.

Çavaş, B., Çavaş, P., Can, B. (2004), "Eğitimde Sanal Gerçeklik" The Turkish Online Journal of Educational Technology, 3(4), 110-116.

Ekinci, E., Özer, U. (2019). "Bir Serbest Zaman Etkinliği Olarak Sanal Gerçeklik" 2. Uluslararası Rekreasyon ve Spor Yönetimi Kongre Kitabı, 2019, 111-112.

Ferhat, S. (2016). "Dijital Dünyanın Gerçekliği, Gerçek Dünyanın Sanallığı Bir Dijital Medya Ürünü Olarak Sanal Gerçeklik” TRT Akademi, 1(2), 724-746.

Heilig M. (1962). US Patent Office, patent no: \#3,050,870 
Kuruüzümcü, R. (2010). "Bir Dijital Ortam ve Sanat Formu Olarak Sanal Gerçeklik” Sanat Dergisi, O(12), 2007, 93-96.

Porett, Tom (1994). "Cyberan considerations" Art Journal, Academic Research Library, 53(3), 32.

Richard I. Land and Ivan E. Sutherland. (1969). "Real-Time, Color, Stereo, Computer Displays," Applied Optics 8(3), 721-723.

Sato, H., Kitahara, I ve Ohta, Y. (2009). "MR-Mirror: A Complex of Real and Virtual Mirrors. In Virtual and Mixed Reality”, (Editör:Randall Shumaker). Springer-Verlag Berlin Heidelberg.

Sanchez, GME., Renterghem, T., Sun, K., Coensel, B., Botteldooren, D. (2017). "Using Virtual Reality for assessing the role of noise in the audio-visual design of an urban public space" Landscape and Urban Planning, 167(98), 107.

Sutherland, I. (1966). “Computer inputs and outputs” Scientific American, 215(3),86-99.

Şekerci, C. (2017), "Sanal Gerçekliğin İç Mimarlık Eğitimine Etkisi”, Yüksek Lisans Tezi, Hacettepe Üniversitesi, Güzel Sanatlar Enstitüsü, Ankara.

Özen, A. (2006). "Mimari Sanal Gerçeklik Ortamlarında Alg1 Psikolojisi” Bilgi Teknolojileri Kongresi IV, Akademik Bilişim 2006, 455-459.

Xiong, F., Zhao, X., Zhang, Y. (2006), "3-D Animation and Virtual Reality” 6. Management and Decision Support Systems, in CIGR Handbook of Agricultural Engineering (Editör: A. Munack). American Society of Agricultural Engineers, 425-434 Michigan, USA.

https://androidcommunity.com /samsung- set- to- come- out- with- anti- sde- amoled- to- improvevr- experience- 20180710/

https://www.emaze.com

http://www.hitl.washington.edu/projects/learning_center/pf/whatisvr.htm

https://www.makeuseof.com/tag/virtual-reality-desktops-save-money-space/

https://nexter.org/technologies-for-shopping

http://www.peertospace.eu/the-unframed-world

https://www.roadtovr.com/samsung-to-demo-gear-vr-motion-controller-at-ces-2016/

https://www.simlabit.com/ medicalvr/ some- virtual- reality- functions- in- the- field- of- medicaleducation- that- you- had- ignored/

http://thirddimensionknowledge.blogspot.com/2011/01/father-of-virtual-reality.html 